\title{
EFECTO DE LA COMPOSICIÓN QUÍMICA DEL AGUA SOBRE SU DESINFECCIÓN FOTOCATALÍTICA
}

\section{EFFECT OF THE CHEMICAL COMPOSITION OF WATER ON ITS PHOTOCATALYTIC DISINFECTION}

\begin{abstract}
Camilo Castro', Carlos Romero², Oscar Salazar², Aristóbulo Centeno4, Sonia A. Giraldo5
${ }^{1}$ Dr. Ing. Química, Ing. Químico, UIS. castro.lopezcamilo@gmail.com; ${ }^{2}$ Ing. Químico, UIS. caferova@gmail.com; ${ }^{3}$ Ing. Químico, UIS. woodyworld24@hotmail.com; ${ }^{4}$ Profesor Titular, Escuela de Ingeniería Química, UIS, Doctor en Ciencias Aplicadas, Universidad Católica de Lovaina, Bélgica. acenteno@uis.edu.co; ${ }^{5}$ Profesora Titular, Escuela de Ingeniería Química, UIS, Doctora en Ciencias Naturales Aplicadas. Centro de Investigaciones en Catálisis (CICAT), Escuela de Ingeniería Química, Universidad Industrial de Santander (UIS), A.A. 678 Bucaramanga, Colombia Fax: 57-7-6344684, e-mail: sgiraldo@uis.edu. co (Dirección para correspondencia).
\end{abstract}

Rev. U.D.C.A Act. \& Div. Cient. 14(1): 117 - 125, 2011

\section{RESUMEN}

En el presente trabajo, se estudió la influencia de la presencia de compuestos inorgánicos en el agua sobre la inactivación bacteriana de ésta, cuando se utiliza un fotocatalizador. Se emplearon matrices artificiales con distintos contenidos de iones $\left(\mathrm{HCO}_{3}\right)^{-}, \mathrm{Cl}$, $\left(\mathrm{SO}_{4}\right)^{2-},\left(\mathrm{HPO}_{4}\right)^{2-}$ por separado y combinados y un agua cruda, obtenida de una fuente hídrica. El microorganismo modelo fue una cepa nativa de Escherichia coli. Se comparó la desinfección aplicando el proceso SODIS (solar disinfection), con el fotocatalítico, utilizando $\mathrm{TiO}_{2}$ Degussa P-25, como fotocatalizador. Los resultados mostraron que la presencia de $\mathrm{Cl}^{-},\left(\mathrm{SO}_{4}\right)^{2-}$ o $\left(\mathrm{HPO}_{4}\right)^{2-}$, incrementa el tiempo de desinfección en los procesos de SODIS y fotocatalítico, de manera proporcional a la cantidad de ión en la reacción, pero en diferente proporción. En los tres casos, el tiempo de desinfección con fotocatalizador es menor que sin éste. La presencia del ion $\left(\mathrm{HCO}_{3}\right)^{-}$también aumenta el tiempo de desinfección en el proceso fotocatalítico, contrario a lo que sucede en el SODIS, para el cual, este tiempo decrece. Además, se evidenció que el tiempo de desinfección efectivo a las $24 \mathrm{~h}$ también es afectado por la presencia de los iones y, que en la mayoría de las reacciones con el fotocatalizador, se obtiene un efecto residual mayor que con el proceso SODIS.

Palabras clave: Fotodesinfección, SODIS, $\mathrm{TiO}_{2}$, Escherichia coli.
SUMMARY

The present work aims to identify the influence of the chemical composition of water on bacterial inactivation using a photocatalyst. Several simulated water matrixes were prepared using different concentrations of $\left(\mathrm{HCO}_{3}\right)^{-}, \mathrm{Cl}$, $\left(\mathrm{SO}_{4}\right)^{2-}$, $\left(\mathrm{HPO}_{4}\right)^{2-}$ on individual suspensions and all together, as well as, water from a natural source. A native strain of Escherichia coli was used as a model microorganism, and $\mathrm{TiO}_{2}$ Degussa P-25 was employed as the photocatalyst. Results show that, in different proportions, the presence of $\mathrm{Cl}^{-},\left(\mathrm{SO}_{4}\right)^{2-}$ or $\left(\mathrm{HPO}_{4}\right)^{2-}$ increases the disinfection time in the SODIS (solar disinfection) and in photocatalytic processes, proportional to the amount of ion in the reaction. In these three cases, the disinfection time in the presence of the photocatalyst was shorter than without it. $\left(\mathrm{HCO}_{3}\right)^{-}$also increased the disinfection time in the photocatalytic process, but contrarily, in the SODIS process, the disinfection time decreases with the concentration of this ion. Additionally, it was proven that the effective disinfection time for $24 \mathrm{~h}$ without bacterial regrowth after irradiation is affected by the presence of these ions, and in most of the reactions, with the photocatalyst the residual effect is greater than the one originated with the SODIS process.

Key words: Photodisinfection, SODIS, $\mathrm{TiO}_{2}$, Escherichia coli. 


\section{INTRODUCCIÓN}

En las últimas décadas, se ha venido estudiando la aplicación de técnicas avanzadas de oxidación (TAOs) al tratamiento de aguas para consumo humano, buscando mejores resultados que con los métodos tradicionales y menores costos de procesamiento (Carp et al. 2004; Conroy et al. 2001; Lonnen et al. 2005; Malato et al. 2009). Una de la técnicas más promisorias, por su universalidad de aplicación, es la desinfección fotocatalítica (DF), que ha mostrado una disminución apreciable en el tiempo de desinfección, comparada con el método SODIS (Solar Disinfection), el cual, ha evidenciado un muy buen desempeño en la adecuación de aguas contaminadas a muy bajo costo (Rincón et al. 2005; Malato et al. 2009; Castro-López et al. 2010).

Cuando se trata agua cruda tomada, de forma directa de una cuenca hídrica, la capacidad de fotodesinfección del $\mathrm{TiO}_{2}$ se reduce considerablemente (Marugán et al. 2008), por la influencia de diferentes componentes orgánicos y/o inorgánicos, que conforman la matriz del agua. El efecto de la composición química del agua en la eficiencia de los procesos de desinfección fotocatalítica es un punto crucial para la aplicación real de esta técnica en campo, puesto que las aguas naturales, usualmente, contienen concentraciones significativas de sustancias orgánicas e inorgánicas (Marugán et al. 2008). La presencia de iones inorgánicos afectan los procesos de desinfección solar y fotocatalítica, retardando la velocidad de inactivación de microorganismos en agua (Alrousan et al. 2009; Marugán et al. 2008), como también disminuye la velocidad de degradación de compuestos orgánicos (Qourzal et al. 2007; Riga et al. 2007).

En experimentos preliminares realizados en nuestro laboratorio, se observó que una cepa Escherichia coli tomada de una fuente hídrica natural ( $E$. coli nativa) era más resistente en los procesos SODIS y DF, que la cepa $E$. coli estándar ATCC 11229. Quek et al. (2008) observaron un comportamiento similar en la inactivación con luz ultravioleta (UV de $\lambda=200-400 \mathrm{~nm}$ ), de la cepa ATCC 11229 y una cepa nativa de $E$. coli; sin embargo, ambas cepas fueron más resistentes que la cepa ATCC 11775 al mismo tratamiento, lo que sugiere que la más sensible tiene procesos de reactivación (inducidos por radiación blanca) menos eficientes, y/o menos enzimas de fotorreactivación, causando que la reparación del daño causado por la luz UV sobre el DNA sea más lenta.

Teniendo en cuenta estos antecedentes, en este trabajo se propuso analizar el comportamiento de una bacteria $E$. coli nativa frente a los procesos SODIS y DF, aplicando matrices de agua simuladas con presencia de los iones $\mathrm{Cl}$, $\left(\mathrm{HCO}_{3}\right)^{-},\left(\mathrm{SO}_{4}\right)^{2-}$ o/y $\left(\mathrm{HPO}_{4}\right)^{2-}$. El fotocatalizador empleado fue el $\mathrm{TiO}_{2}$ comercial P-25 (Evonik; antes Degussa), el cual, presenta una alta fotoactividad hacia la inactivación de microorganismos (Christensen et al. 2003; Gumy et al. 2006; Herrman, 2010; Smith et al. 2000). Se utilizó la E. coli como microorganismo modelo por ser indicadora de la contaminación microbiológica del agua y por sus facilidades de cultivo y de aislamiento. Además, se analizó el efecto post irradiación de cada reacción, para determinar el tiempo de desinfección efectivo, después de un periodo en la oscuridad de $24 \mathrm{~h}\left(\mathrm{TDE}_{24}\right)$.

\section{MATERIALES Y MÉTODOS}

Los reactivos aplicados fueron de grado analítico: $\mathrm{CaHCO}_{3}$ (Carlo Erba), $\mathrm{MgSO}_{4}$ (Merck), $\mathrm{Na}_{2} \mathrm{PO}_{4}$ (Carlo Erba), $\mathrm{NaCl}$ (Merck) $\mathrm{HCl}$ (Merck), $\mathrm{NaOH}$ (Merck) y el $\mathrm{TiO}_{2}$ comercial (Degussa P-25) con 70:30 anatasa:rutilo, área superficial $55 \pm 15 \mathrm{~m}^{2} / \mathrm{g}$ y tamaño de partícula promedio de $30 \mathrm{~nm}$. Se utilizó, como referencia para la preparación del agua simulada, las concentraciones correspondientes al agua de una fuente natural que alimenta el acueducto de Floridablanca, Santander, Colombia (Puente Rojo de río Frío), del cual, se encontraron las siguientes concentraciones de los iones estudiados: $\left(\mathrm{HPO}_{4}\right)^{-}=7 \times 10^{-2} \mathrm{mg} / \mathrm{L},\left(\mathrm{SO}_{4}\right)^{2-}=$ $3,8 \mathrm{mg} / \mathrm{L}, \mathrm{Cl}^{-}=6,7 \mathrm{mg} / \mathrm{L},\left(\mathrm{HCO}_{3}\right)^{-}=48,1 \mathrm{mg} / \mathrm{L}$.

Preparación del cultivo bacteriano para las reacciones de desinfección: Se manipuló una cepa E. coli nativa, extraída de un lago de agua estancada. El cultivo, se realizó tomando dos colonias de un cultivo previo, en un medio enriquecido agar recuento (AR, Merck), que se inoculó en $10 \mathrm{~mL}$ de medio nutritivo Luria Bertani (LB); triptona (Oxoid) al $1 \% \mathrm{p} / \mathrm{v}$; extracto de levadura (Oxoid) al $0,5 \% \mathrm{p} / \mathrm{v}$ y $\mathrm{NaCl}$ (Carlo Erba) al 1\% p/v. El inoculo, se mantuvo durante 2,5h, con una agitación constante de 100rpm y una temperatura fija de $35 \pm 2^{\circ} \mathrm{C}$. Luego, se diluyó en $90 \mathrm{~mL}$ de medio LB; se mantuvo en las mismas condiciones de agitación y de temperatura durante $10 \mathrm{~h}$, hasta alcanzar la fase estacionaria de crecimiento. De allí, se tomó una alícuota de $2 \mathrm{~mL}$, se centrifugó durante $10 \mathrm{~min}$ a $3000 \mathrm{rpm}$, se recuperó el pellet de biomasa celular, se diluyó en $1 \mathrm{~mL}$ de solución salina $(0,85 \% \mathrm{p} / \mathrm{v})$ esterilizada; este procedimiento, se repitió dos veces. Al final el pellet de biomasa, se diluyó en $1 \mathrm{~mL}$ de agua destilada y esterilizada y se agregó al reactor.

Reacciones de desinfección: Se realizaron en frascos de borosilicato con $50 \mathrm{~mL}$ de agua destilada y esterilizada con el ion $\mathrm{Cl}^{-},\left(\mathrm{HCO}_{3}\right)^{-},\left(\mathrm{SO}_{4}\right)^{2-}$ o $\left(\mathrm{HPO}_{4}\right)^{2-}$, a una concentración entre 0 y $5 \mathrm{mmol} / \mathrm{L}$. Se emplearon $0,02 \mathrm{~g}$ de $\mathrm{TiO}_{2}$ como fotocatalizador, para obtener una concentración de 0,4 $\mathrm{g} / \mathrm{L}$, y $1 \mathrm{~mL}$ de suspensión bacteriana, preparada como se describió anteriormente, para alcanzar una concentración aproximada de $10^{7}$ unidades formadoras de colonia por unidad de volumen (UFC/mL); se ajustó el pH en 7,0 \pm 0,2 
con solución de $\mathrm{HCl}$ o $\mathrm{NaOH}$, según el caso y se mantuvieron en la oscuridad durante $30 \mathrm{~min}$, con agitación constante de 100rpm, antes de iniciar la irradiación. Los reactores, se irradiaron utilizando una cámara suntest (CPS+, ATLAS), con temperatura y radiación controlada y con longitudes de onda de irradiación entre 300 y $800 \mathrm{~nm}$, con $7 \%$ de los fotones emitidos, entre 300 y 400nm. La intensidad de radiación aplicada fue de $400 \mathrm{~W} / \mathrm{m}^{2}$ y la temperatura, de $35^{\circ} \mathrm{C}$. El tiempo de reacción fue de 3 h y durante este tiempo, se tomaron muestras, que se analizaron por un procedimiento estándar de diluciones en serie. De cada dilución decimal, se sembraron $10 \mu \mathrm{L}$ por duplicado en AR y se incubaron a $35 \pm 2^{\circ} \mathrm{C}$ durante $18 \mathrm{~h}$, para el posterior conteo de las colonias sobrevivientes. Adicionalmente, se llevaron a cabo reacciones $\sin \mathrm{TiO}_{2}$ (SODIS) y las de referencia; sin el ion y $\sin \mathrm{TiO}_{2}$ ni el ion.

Con el propósito de conocer el tiempo de desinfección efectivo $\mathrm{TDE}_{24}$, que es el tiempo mínimo al que debe estar la bacteria bajo irradiación para que después de un periodo de $24 \mathrm{~h}$ en la oscuridad no se evidencie su recrecimiento, se tomó una alícuota de cada muestra tomada durante la reacción de desinfección y se guardó en la oscuridad, por un periodo de $24 \mathrm{~h}$, para luego ser diluida y sembrada en AR. Se usó el mismo procedimiento estándar, manejado para el análisis de las muestras tomadas durante las reacciones.

Además, se realizaron reacciones con agua cruda y agua destilada con los cuatro iones simultáneamente a las concentraciones del agua cruda encontradas en el río Frío y a tres niveles de irradiación $\left(250,400\right.$ y $\left.700 \mathrm{~W} / \mathrm{m}^{2}\right)$. Las reacciones con agua cruda, se siguieron con el procedimiento descrito anteriormente, pero haciendo la siembras en un medio de cultivo selectivo agar MacConkey (AMC; Oxoid), para detectar coliformes totales. La concentración de coliformes totales detectada en el agua de río Frío fue de $5 \times 10^{-4} \mathrm{UFC} / \mathrm{mL}$.

\section{RESULTADOS Y DISCUSIÓN}

Efecto de los iones sobre el proceso de desinfección: En las figuras 1 a 4, se muestra el efecto de cada uno de los iones estudiados $\mathrm{Cl},\left(\mathrm{HCO}_{3}\right)^{-},\left(\mathrm{SO}_{4}\right)^{2-},\left(\mathrm{HPO}_{4}\right)^{2-}$ sobre la $E$. coli nativa, durante los procesos DF y SODIS. En estas figuras, se observa que la presencia de los iones en el agua logra alterar el comportamiento de la bacteria en los dos procesos de desinfección.

La figura 1 muestra que el ion $\mathrm{Cl}^{-}$tiene un efecto inhibitorio en la DF y que este efecto aumenta a medida que se incrementa la concentración del ion en el agua. El tiempo de desinfección aumenta 60 min para el agua que contiene $5 \mathrm{mmol} / \mathrm{L}$, comparada con el agua sin iones $\mathrm{Cl}$. Por otro lado, para el proceso SODIS, la influencia del $\mathrm{Cl}^{-}$es menor que para la DF, pues la mayor concentración usada del ion $\mathrm{Cl}^{-}(5 \mathrm{mmol} / \mathrm{L})$ en SODIS aumentó el tiempo de desinfección en $40 \mathrm{~min}$, mientras que usando bajas concentraciones, como 0,086 y $0,5 \mathrm{mmol} / \mathrm{L}$, se registró un comportamiento similar a la desinfección solar sin el ion.

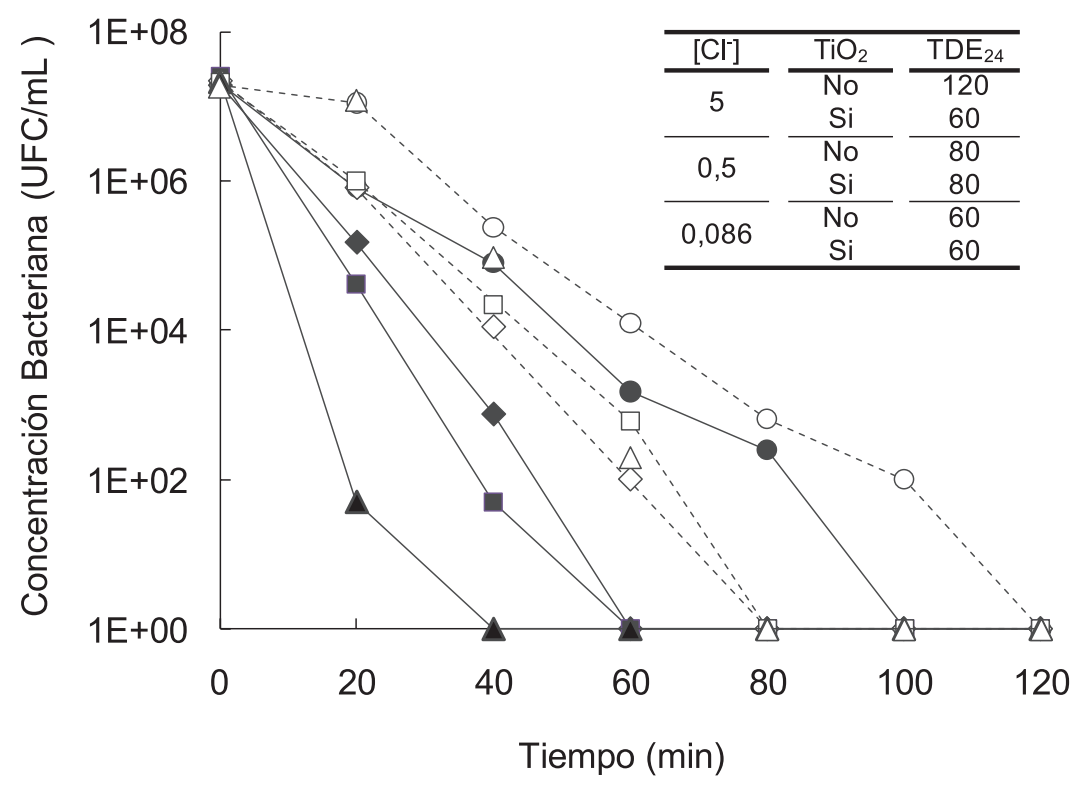

Figura 1. Comportamiento de la E. coli en las reacciones de DF (símbolos llenos) y SODIS (símbolos vacíos), a diferentes concentraciones del ion

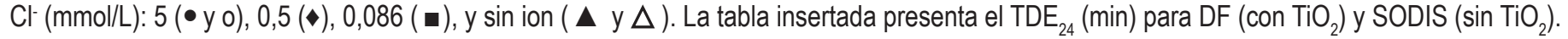


La figura 2 indica que el ion $\left(\mathrm{HCO}_{3}\right)^{-}$tambien tiene un efecto inhibitorio en el proceso de DF a las concentraciones analizadas $(5 ; 0,695$ y $0,5 \mathrm{mmol} / \mathrm{L})$, mientras que en el proceso SODIS, empleando una concentración de $5 \mathrm{mmol} / \mathrm{L}$ de $\left(\mathrm{HCO}_{3}\right)^{-}$existe un efecto ligeramente favorable disminuyendo la velocidad de inactivación; sin embargo, no se evidenciaron cambios en el tiempo de desinfección.
La figura 3 señala que el ion $\left(\mathrm{SO}_{4}\right)^{2-}$ inhibe los procesos de DF y SODIS. En la DF, la influencia de la concentración es muy leve, mientras que para SODIS, a una concentración de $5 \mathrm{mmol} / \mathrm{L}$, se observa un efecto negativo notable. Concentraciones menores del ion, como 0,043 y 0,5mmol/L no causaron cambios significativos en ninguno de los procesos.

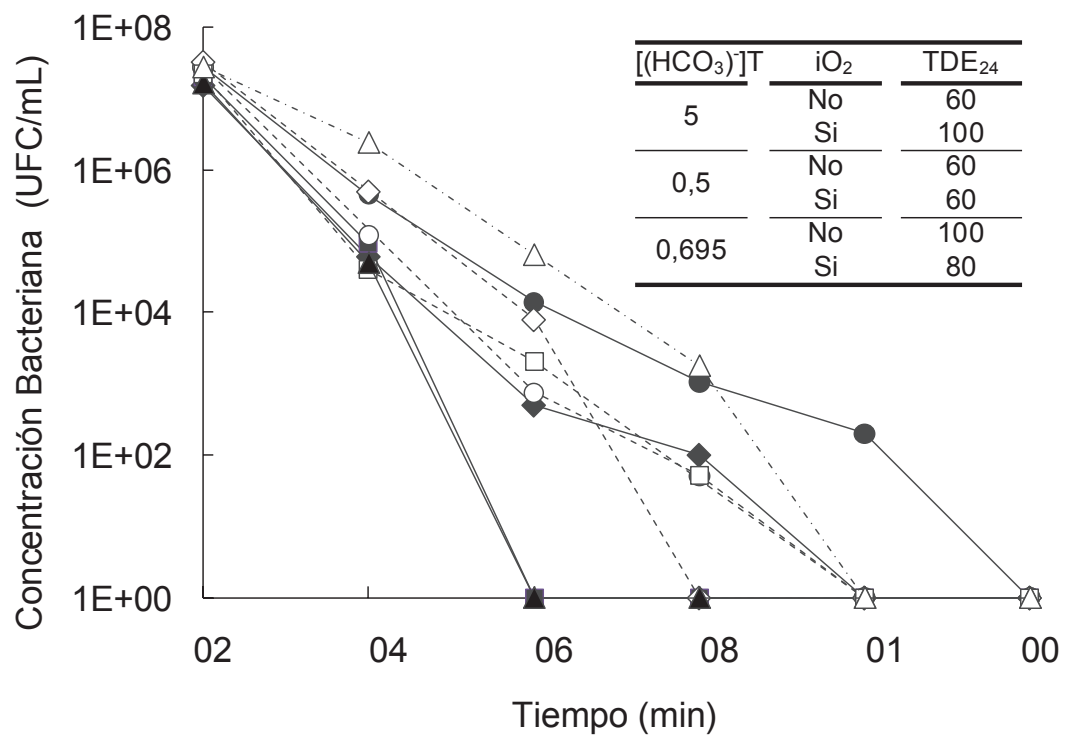

Figura 2. Comportamiento de la E. coli en las reacciones de DF (símbolos llenos) y SODIS (símbolos vacios), a diferentes concentraciones del

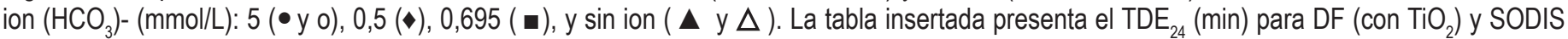
$\left(\sin \mathrm{TiO}_{2}\right)$.

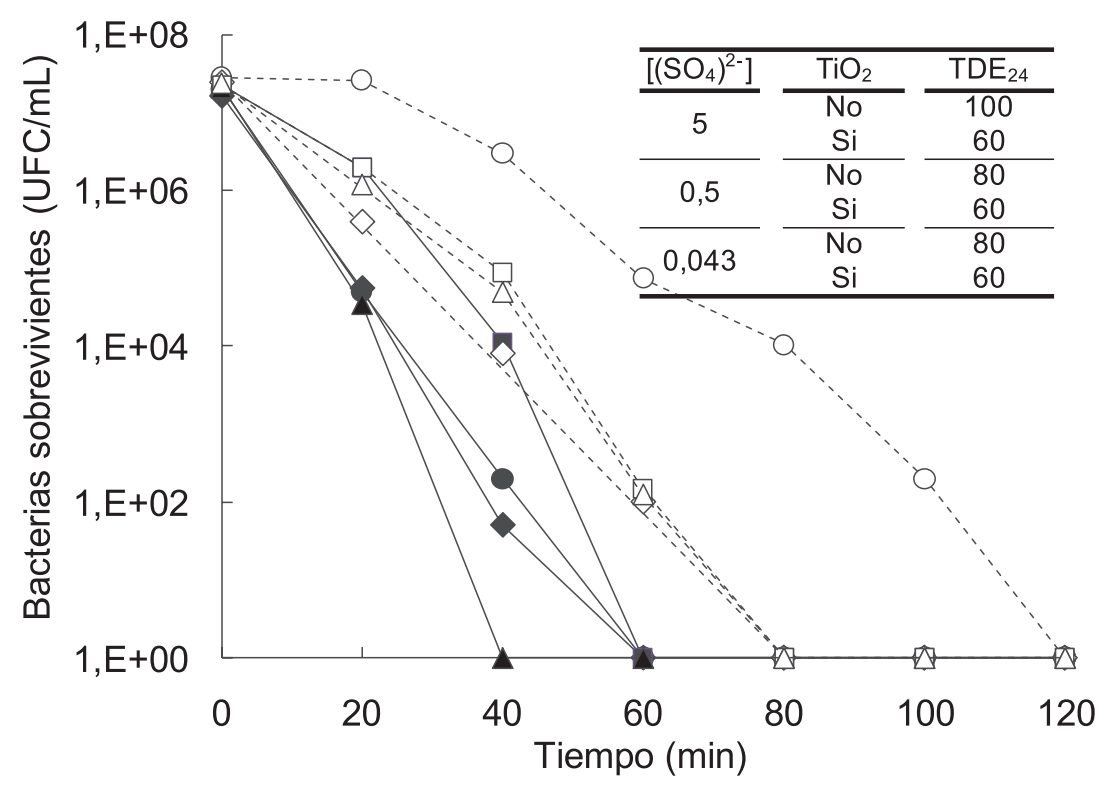

Figura 3. Comportamiento de la $E$. coli en las reacciones de DF (símbolos llenos) y SODIS (símbolos vacíos), a diferentes concentraciones del ion

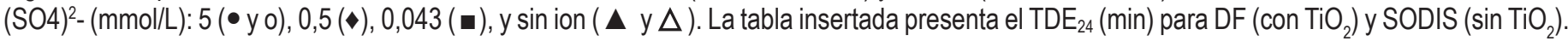


El ion $\left(\mathrm{HPO}_{4}\right)^{2-}$ tiene un efecto inhibitorio en el intervalo de concentraciones (5, 0,5 y $9,6 \times 10^{-4} \mathrm{mmol} / \mathrm{L}$ ) analizado, como se observa en la figura 4; no obstante, en la DF el efecto es mucho mayor que para SODIS, en donde el efecto de una alta concentración de $5 \mathrm{mmol} / \mathrm{L}$ causó un pequeño incremento de $20 \mathrm{~min}$, en el tiempo de desinfección.

El efecto inhibitorio a altas concentraciones de los diferentes iones, teniendo en cuenta el tiempo de inactivación, se puede resumir así:

DF: $\left(\mathrm{HPO}_{4}\right)^{2-}>\left(\mathrm{HCO}_{3}\right)^{-} \gg \mathrm{Cl}^{-}>\left(\mathrm{SO}_{4}\right)^{2-}>$ sin ión

SODIS: $\mathrm{Cl}^{-} \gg\left(\mathrm{SO}_{4}\right)^{2-} \geq\left(\mathrm{HPO}_{4}\right)^{2-}>$ sin ión $>\left(\mathrm{HCO}_{3}\right)^{-}$.

La influencia negativa de cada uno de los iones en la DF, se puede interpretar considerando, en primera instancia, que los aniones $\left(\mathrm{A}^{-}\right)$reducen la tasa de desinfección al neutralizar las especies oxidantes $\left({ }^{\circ} \mathrm{O} x\right)$, tales como los radicales ${ }^{\circ} \mathrm{OH}$ y $\mathrm{HO}_{2} \cdot$ de acuerdo a la Ec. (1)

$\cdot \mathrm{O} x+\mathrm{A}^{-} \rightarrow \mathrm{A}^{\cdot-}+\mathrm{Ox}$

Generalmente, los radicales formados $\left(\mathrm{A}^{\circ}\right)$ tienen una menor capacidad oxidativa que los radicales que se producen durante el proceso fotocatalítico. Un ejemplo de la neutralización de las especies altamente oxidantes, se muestra en las Ecs. (2) y (3) con el bicarbonato. $\cdot \mathrm{OH}+\left(\mathrm{HCO}_{3}\right)^{-} \cdot \mathrm{CO}_{3}^{\cdot-}+\mathrm{H}_{2} \mathrm{O}$
$\cdot \mathrm{OH}+\mathrm{CO}_{3}^{2-"} \mathrm{CO}_{3}^{\cdot-}+\mathrm{OH}^{-}$

Además, la competencia por los huecos generados en el fotocatalizador Ec. (4), es otro factor que podría inhibir el proceso de DF, al disminuir la cantidad de radicales altamente oxidantes, que se forman durante el proceso (Chong et al. 2010).

$\mathrm{A}^{-}+\mathrm{h}^{+} \rightarrow \mathrm{A}^{\cdot}$

La inhibición también se podría dar por la adsorción de los aniones en la superficie del fotocatalizador, lo cual, evita que los rayos UV alcancen las partículas del fotocatalizador, disminuyendo la generación de radicales oxidantes (Rincón E Pulgarín, 2004). Si se tiene en cuenta que el efecto de inhibición podría depender de la cantidad adsorbida del ion sobre la superficie de las partículas del $\mathrm{TiO}_{2}$, entonces, de acuerdo a los resultados, el orden de afinidad entre cada uno de los iones y la superficie del $\mathrm{TiO}_{2}$ sería el mismo que el observado para la efectividad de la DF, nombrado anteriormente.

Aunque las anteriores interpretaciones también se aplicarían para el ion sulfato, en este caso, se puede agregar que el radical $\mathrm{SO}_{4}{ }^{\bullet-}$ que se forma (Ec. (5)) es uno de los principales intermedios oxidantes, que conllevan a la formación de $\mathrm{CO}_{2}$

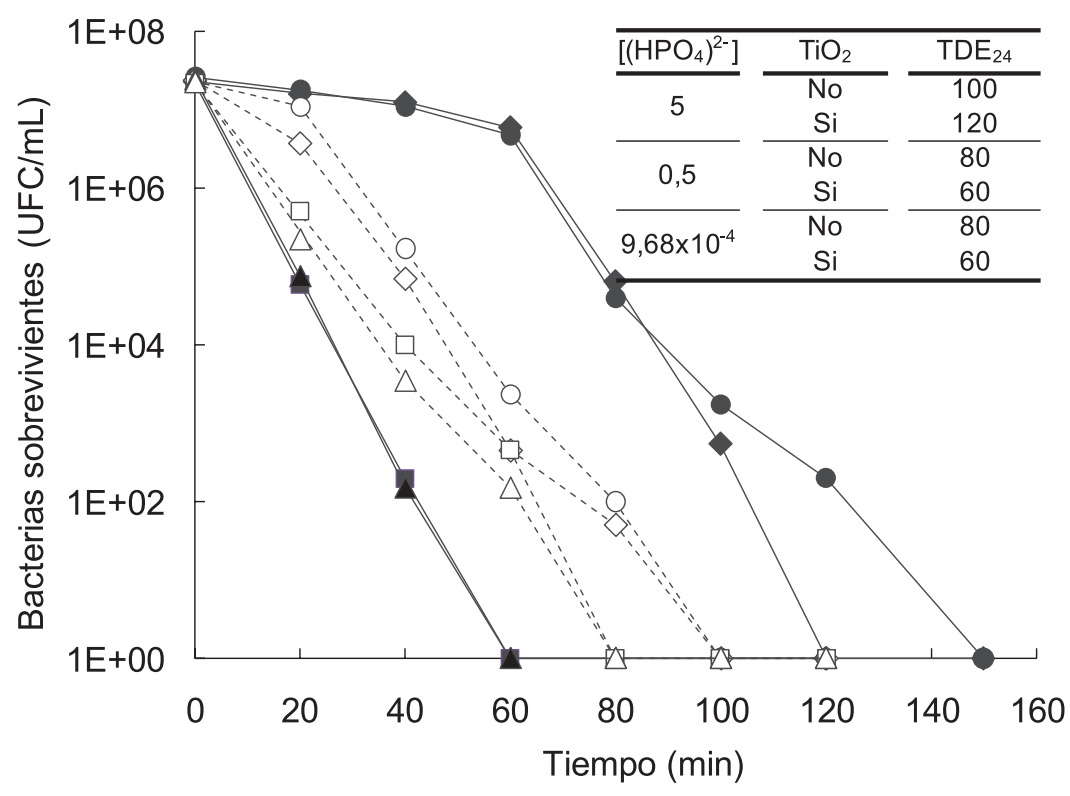

Figura 4. Comportamiento de la E. coli en las reacciones de DF (símbolos llenos) y SODIS (símbolos vacíos), a diferentes concentraciones del

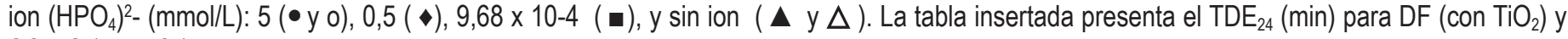
SODIS $\left(\sin \mathrm{TiO}_{2}\right)$. 
bajo radiación UV, Ec. (6), (Abdullah et al. 1990). Esta es una buena razón para creer que el $\mathrm{SO}_{4} \bullet^{\bullet-}$ puede oxidar la materia orgánica (MatOrg), también adsorbida en la superficie del $\mathrm{TiO}_{2}$, de acuerdo a las Ecs. (5) y (6).

$\left(\mathrm{SO}_{4}\right)^{2-}+{ }^{\cdot} \mathrm{OH}$ " $\mathrm{SO}_{4} \cdot{ }^{--}+\mathrm{OH}^{-}$

$\mathrm{SO}_{4} \cdot-$ MatOrg " $\mathrm{CO}_{2}+$ otros

El hecho que entre los iones estudiados el sulfato tenga el menor efecto sobre la desinfección puede estar relacionado con la reacción entre el $\mathrm{SO}_{4}{ }^{--}$y los diferentes compuestos orgánicos adsorbidos en la superficie del $\mathrm{TiO}_{2}$ (Ec. (6)); esta reacción es más rápida que la correspondiente con otros radicales, como el $\mathrm{H}_{2} \mathrm{PO}_{4} \cdot$ (Abdullah et al. 1990), retrasándose la inactivación de la bacteria.

Adicionalmente, se conoce que las constantes de las velocidades de formación de los radicales $\mathrm{Cl}_{2}{ }^{-}$y $\mathrm{SO}_{4}{ }^{-}$, provenientes de la reacción entre los radicales $\mathrm{Cl}^{-}$y $\left(\mathrm{SO}_{4}\right)^{2-}$ (Ec. 1 , con ${ }^{\circ} \mathrm{O} x={ }^{\circ} \mathrm{OH}$ ), son $4,3 \times 10^{9}$ y $3,5 \times 10^{5} \mathrm{~mol} / \mathrm{L} . \mathrm{s}$, respectivamente (Malato et al. 2009), por lo tanto, es de esperarse que la diferencia en la inhibición de la DF por el ión $\mathrm{Cl}^{-}$sea mayor que la del ión $\left(\mathrm{SO}_{4}\right)^{2-}$, ya que la velocidad de la reacción de atrapamiento del ${ }^{\circ} \mathrm{OH}$ es mayor con el primero.

Por otro lado, la acción positiva del $\left(\mathrm{HCO}_{3}\right)^{-}$en los procesos SODIS (Figura 2), se puede explicar por la alta absorción del anión por la $E$. coli que altera la naturaleza de la membrana celular y la vuelve más sensible a la exposición de la radiación solar simulada (Rincón E Pulgarín, 2004). Por el contrario, en presencia de $\mathrm{TiO}_{2}$ este efecto se ve disminuido, probablemente, por la absorción del ion sobre la superficie del fotocatalizador, lo que disminuye la interacción con la membrana del microorganismo y, a la vez, reduce la formación de radicales oxidantes, retardando la velocidad de inactivación en la DF.

Para el caso del fosfato, se sabe que éste es adsorbido por la superficie de las partículas de $\mathrm{TiO}_{2}$, formando una capa que inhibe la absorción de luz y, por lo tanto, su fotoactivación (Chong et al. 2010); además, la adsorción del ion $\left(\mathrm{HPO}_{4}\right)^{2-}$ por el $\mathrm{TiO}_{2}$ es mayor que en el caso de $\mathrm{Cl},\left(\mathrm{HCO}_{3}\right)^{-}$y $\left(\mathrm{SO}_{4}\right)^{2-}$ (Rincón $\mathcal{E}$ Pulgarín, 2004). Por esta razón, se genera una inhibición en la generación de radicales, lo que aumenta el tiempo de desinfección total. Adicionalmente, se conoce que el $\left(\mathrm{HPO}_{4}\right)^{2-}$ sirve como nutriente para los microorganismos y sostiene el crecimiento de las bacterias en las aguas naturales (Sathasivan et al. 1997). Lo anterior podría mejorar las condiciones en el medio para las bacterias y así promover la generación y liberación de enzimas, como la superoxidodismutasa y la catalasa, que pueden contrarrestar los efectos de los radicales oxidantes, como el superóxido $\left(\mathrm{O}_{2}{ }^{-}\right)$y el hidroperóxido $\left(\mathrm{HO}_{2}{ }^{\circ}\right)$, respectivamente.

Al comparar los valores de los $\mathrm{TDE}_{24}$ en las tablas insertadas en cada figura (1-4), se observa, en la mayoría de las reacciones, que éste se reduce con la presencia de $\mathrm{TiO}_{2}$.

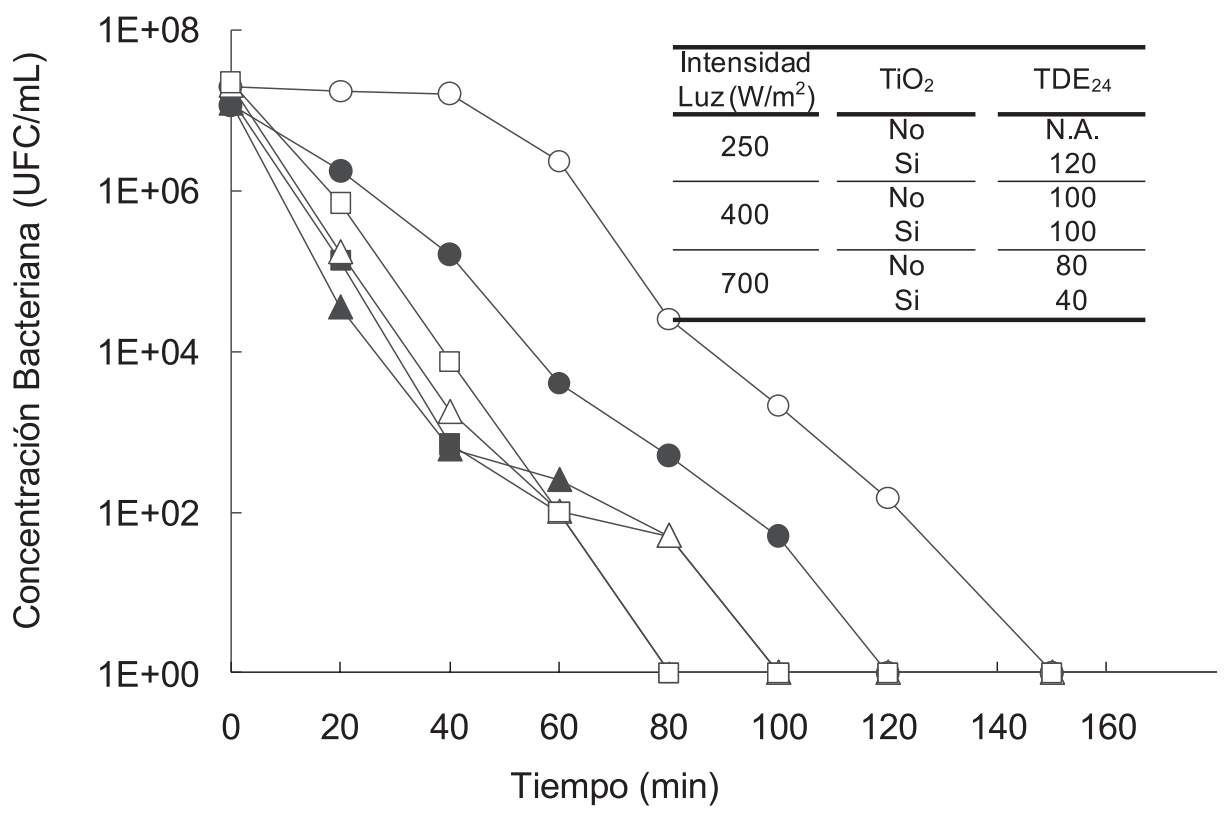

Figura 5. Comportamiento de la E. coli en el agua sintética en las reacciones de DF (símbolos llenos) y SODIS (símbolos vacíos), a diferentes intensidades de irradiación $\left(\mathrm{W} / \mathrm{m}^{2}\right)$ : $250\left(\bullet\right.$ y o), $400\left(\boldsymbol{\Delta}\right.$ y $\Delta$ ), $700\left(\bullet \mathrm{y}\right.$ 口). La tabla insertada presenta el TDE $24(\mathrm{~min})$ para DF $\left(\operatorname{con} \mathrm{TiO}_{2}\right)$ y SODIS $\left(\sin \mathrm{TiO}_{2}\right)$. N.A.: No Alcanzado. 
Adicionalmente, con la presencia de cada ion sin $\mathrm{TiO}_{2}$, se percibe un efecto muy similar al observado en el tiempo de desinfección, es decir, para la DF el $\left(\mathrm{HPO}_{4}\right)^{2-}$ y el $\left(\mathrm{HCO}_{3}\right)^{-}$a alta concentración $(5 \mathrm{mmol} / \mathrm{L})$ son los iones que causan la mayor inhibición de la desinfección, al igual que son los que más aumentan el $\operatorname{TDE}_{24}$ (120 y 100min, respectivamente). Esto es debido, posiblemente, a que el fosfato puede actuar como nutriente para la bacteria, como ya se mencionó. En el caso de los carbonatos es debido a su acción altamente negativa sobre la DF, lo que provoca un aumento en el periodo de inactivación y así mismo en el $\mathrm{TDE}_{24}$.

Efecto de la competición de los iones: La figura 5 muestra el comportamiento de las bacterias cuando son expuestas a los procesos SODIS y DF en una matriz de agua simulada con las concentraciones de iones semejantes a las del agua cruda. En general, se observa que el tiempo de desinfección, en el proceso de DF aumenta cuando están presentes los cuatro iones en comparación de cuando se evalua su acción por separado a una potencia de $400 \mathrm{~W} / \mathrm{m}^{2}$. A intensidades de luz, entre 400 y $700 \mathrm{~W} / \mathrm{m}^{2}$, no existe una diferencia apreciable entre los efectos bactericidas de SODIS y DF, lo que puede ser debido al efecto directo de la radiación unicamente, puesto que a $400 \mathrm{~W} / \mathrm{m}^{2}$ la radiación UV sobre las bacterias es suficiente para inactivarlas, en tiempos relativamente cortos, lo que no permite apreciar la capacidad foto-oxi-reductora del $\mathrm{TiO}_{2}$. Sólo a intensidades bajas, como $250 \mathrm{~W} / \mathrm{m}^{2}$, se logra apreciar el efecto del $\mathrm{TiO}_{2}$, en la reducción del tiempo de desinfección.
Desinfección del agua natural de río Frío: En la figura 6 , se registra el comportamiento de coliformes que se encuentran presentes en el agua cruda frente a los dos procesos SODIS y DF. Se observa que el comportamiento de los microorganismos en ambos procesos es el esperado, mostrando una aceleración en la reacción de desinfección a intensidades de luz de $700 \mathrm{~W} / \mathrm{m}^{2}$. Se puede apreciar que la presencia del TiO2 aumenta la velocidad de desinfección, lo que confirma que la DF es una tecnología más eficiente que la SODIS, en el tratamiento de aguas crudas.

En las tablas insertadas en las figuras 5 y 6 , se señala que en todos los casos el $\mathrm{TDE}_{24}$ es menor en la DF que para el proceso SODIS. Lo que indica, que el efecto neto de oxidación de los radicales producidos en la DF es más efectivo que el proceso SODIS, aun cuando se usan los cuatro iones estudiados en conjunto. Se advierte, además, que el tiempo necesario para la inactivación es mayor que el correspondiente $\mathrm{TDE}_{24}$. El caso más representativo de este efecto es en el agua sintética, tratada a $700 \mathrm{~W} / \mathrm{m}^{2}$; durante la reacción el tiempo de desinfección fue de 80min (Figura 5), pero después de $24 \mathrm{~h}$, en la oscuridad, la muestra que fue tomada a los $40 \mathrm{~min}$ de reacción no mostró presencia alguna de la $E$. coli, lo que reveló la efectividad de la presencia del $\mathrm{TiO}_{2}$, sometido a altas intensidades de luz. Lo anterior representa un factor importante en el establecimiento de condiciones de irradiación de suspensiones E.coli- $\mathrm{TiO}_{2}$ en la DF, pues aunque no se haya alcanzado la desinfección total aparente (medida en muestras frescas), sí se ha

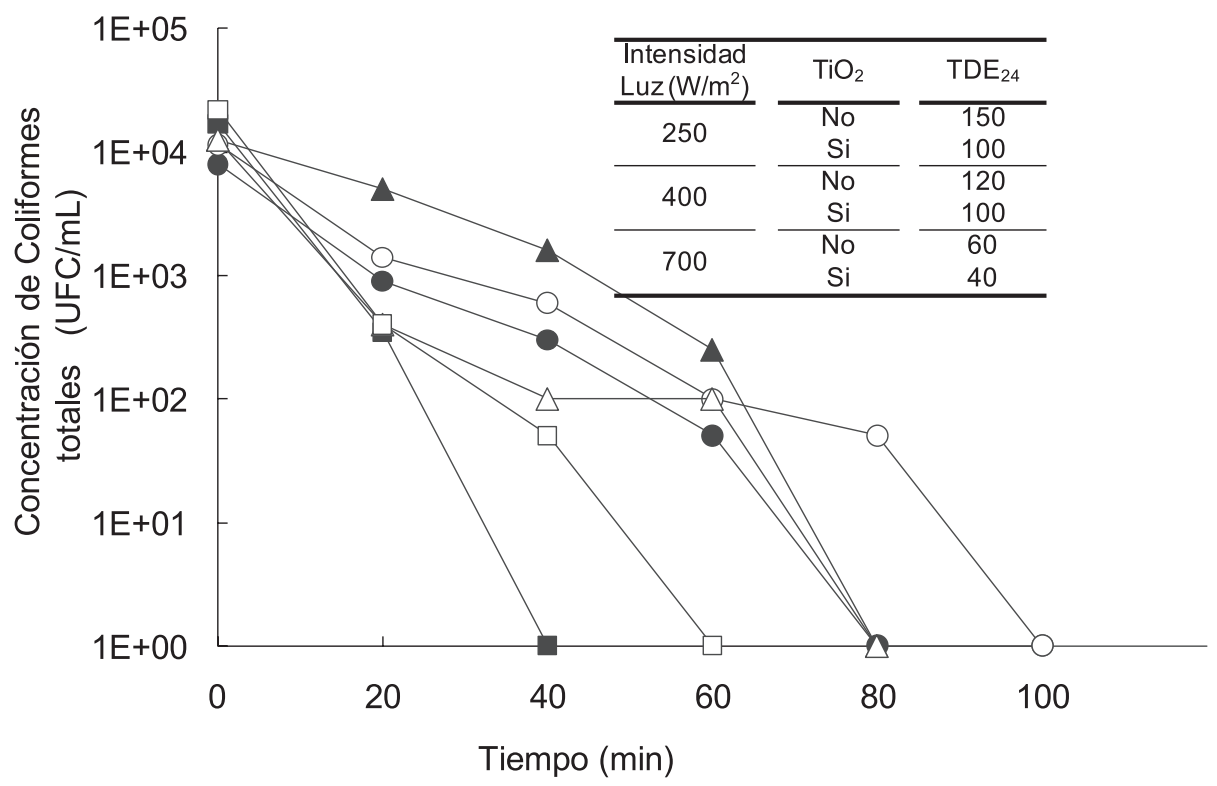

Figura 6. Comportamiento de coliformes totales del agua cruda en las reacciones de DF (símbolos llenos) y SODIS (símbolos vacíos), a diferentes

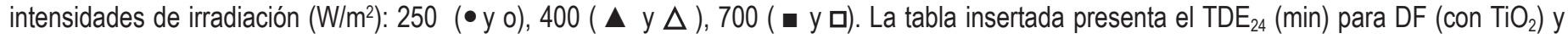
SODIS $\left(\sin \mathrm{TiO}_{2}\right)$. 
alcanzado un daño tal que, a los 40 min de irradiación, el microorganismo no puede recuperarse y muere. Por lo tanto, una vez alcanzado este estado no se necesitaría continuar la irradiación; sin embargo, a bajas potencias de irradiación es probable que no se genere la cantidad suficiente de radicales oxidantes para inactivar el microorganismo, lo que permite a la bacteria tener una mayor oportunidad para contrarrestar dichos radicales, gracias a sus mecanismos de defensa y de recuperación (Sommer et al. 1998), lo que aumenta el $\mathrm{TDE}_{24}$.

Se debe tener en cuenta que la concentración inicial de microorganismos en el agua de la fuente natural $\left(\sim 10^{4}\right.$ UFC/mL, Figura 6) es tres órdenes de magnitud menor, que la concentración inicial, usada en los experimentos con agua sintética $\left(\sim 10^{7} \mathrm{UFC} / \mathrm{mL}\right.$, Figura 5$)$. Debido a esto, la inactivación se lleva a cabo en tiempos más cortos, en el caso del agua de río; no obstante, los $\mathrm{TDE}_{24}$ son similares en ambos experimentos. Esto indica, que la cantidad de especies oxidantes producidas durante la irradiación del $\mathrm{TiO}_{2}$, por ejemplo, a $700 \mathrm{~W} / \mathrm{m}^{2}$, sobrepasa la cantidad necesaria para inactivar totalmente una población de microorganismos de $\sim 10^{4} \mathrm{UFC} / \mathrm{mL}$, en un tiempo de tratamiento de $\sim 60 \mathrm{~min}$. De hecho, este tiempo de tratamiento es suficiente para desactivar una población de $E$. coli con una concentración mil veces mayor, como en el caso del agua sintética, mostrada en la figura 5. Por consiguiente, es posible determinar el tiempo de irradiación necesario en la DF sin sobreestimar el potencial de oxidación del sistema de tratamiento, respecto a la concentración inicial de microorganismos, como ya se mencionó.

Adicionalmente, y contrario a lo esperado, como se observa en la figura 5, no se presentó una suma de los efectos de disminución de la DF de los iones por separado en el agua sintética, sino que la efectividad de la misma, con una concentración de iones análoga a la del agua de río, fue similar a la del proceso de desinfección solar. Se ha observado que el efecto de los iones parece contrarrestarse, cuando se aplica $\mathrm{TiO}_{2}$ a la DF de aguas reales (Marugan et al. 2010) e, incluso, Gomes et al. (2009) observaron este efecto en la desinfección solar en estudios, a nivel de planta piloto. Entonces, es probable que el efecto sobre la superficie del $\mathrm{TiO}_{2}$ por adsorción de los iones prevalezca sobre el atrapamiento de radicales oxidantes en fase homogénea, de modo que la superficie queda cubierta por una misma cantidad de iones que en el caso de su análisis en forma individual, y así la efectividad es similar bajo diferentes potencias de irradiación. De hecho, se ha observado el atrapamiento de los $\mathrm{h}^{+}$fotogenerados por iones inorgánicos (Ec. 4), adsorbidos en la superficie del $\mathrm{TiO}_{2}$, como Cl- $\left(\mathrm{SO}_{4}\right)^{2-}$ $\mathrm{y} \mathrm{NO}_{3}{ }^{-}$, disminuyendo la fotoactividad hacia la degradación de compuestos orgánicos (Mahmoodi et al. 2007). Este efecto, se percibe en todos los casos, exceptuando la curva de desinfección, a $250 \mathrm{~W} / \mathrm{m}^{2}$, en agua sintética, en donde es probable que a bajas potencias de irradiación prevalezca el efecto de iones desestabilizadores de la membrana del microorganismo, que generan un aumento en su sensibilidad a la fotoinactivación con $\mathrm{TiO}_{2}$ y a la radiación solar simulada; sin embargo, este efecto no se observa para el agua natural (Figura 6), lo que indica que no se presenta en una matriz real.

En este trabajo, se determinó la influencia de los iones $\left(\mathrm{HCO}_{3}\right)^{-} \mathrm{Cl}^{-},\left(\mathrm{SO}_{4}\right)^{2-}$ y/o $\left(\mathrm{HPO}_{4}\right)^{2-}$ y su concentración en la fotodesinfección de agua. En todos los casos, su efecto fue negativo y proporcional a la cantidad de iones presente. El $\left(\mathrm{HPO}_{4}\right)^{2-}$ es el ión que más inhibe la fotodesinfección, debido a su fuerte adsorción sobre la superficie del $\mathrm{TiO}_{2}$ y, además, sirve como nutriente de las bacterias lo que, posiblemente, mejora las condiciones metabólicas, contrarrestándose el efecto de los radicales oxidantes.

En la desinfección de un agua sintética con todos los iones presentes, el efecto del fotocatalizador es apreciable a intensidades de luz bajas $\left(250 \mathrm{~W} / \mathrm{m}^{2}\right)$. Al aumentar la intensidad de la radiación $\left(700 \mathrm{~W} / \mathrm{m}^{2}\right)$ mejora la acción de desinfección, pero no se aprecia la acción del fotocatalizador. Este aumento de intensidad, además, genera un efecto neto oxidativo, que disminuye el tiempo de desinfección efectivo $\left(\mathrm{TDE}_{24}\right)$ del proceso.

Agradecimientos: Este trabajo, se realizó gracias al soporte financiero de COLCIENCIAS, el SENA y la UIS, en el marco del proyecto "Desarrollo de procesos heliofotocatalíticos para la producción de agua potable en pequeñas comunidades en Santander" (código 1102341-19419). Conflicto de intereses: El manuscrito fue preparado y revisado con la participación de todos los autores, quienes declaramos que no existe ningún conflicto de intereses que ponga en riesgo la validez de los resultados presentados.

\section{BIBLIOGRAFÍA}

1. ABDULLAH, M.; LOW, G.K.; MATTHEWS, R. 1990. Effects of common inorganic anions on rates of photocatalytic oxidation of organic carbon over illuminated titanium dioxide. J. Physics Chem. 94(17):6820-6825.

2. ALROUSAN, D.; DUNLOP, P.; MCMURRAY, T.; BYRNE, J. 2009. Photocatalytic inactivation of $E$. coli in surface water using immobilised nanoparticle $\mathrm{TiO}_{2}$ films. Water Res. 43(1):47-54.

3. CARP, O.; HUISMAN, C.L.; RELLER, A. 2004. Photoinduced reactivity of titanium dioxide. Progress in Solid State Chemistry. 32(1):33-177. 
4. CASTRO-LÓPEZ, C.A.; CENTENO, A.; GIRALDO, S.A. 2010. Fe-modified $\mathrm{TiO}_{2}$ photocatalysts for the oxidative degradation of recalcitrant water contaminants. Catalysis Today. 157(1):119-124.

5. CHRISTENSEN, P.A.; CURTIS, T.P.; EGERTON, T.A.; KOSA, S.; TINLIN, J.R. 2003. Photoelectrocatalytic and photocatalytic disinfection of $E$. coli suspensions by titanium dioxide. Applied Catalysis B. 41(4):371-386.

6. CONROY, R.; MEEGAN, M.; JOYCE, T.; MCGUIGAN, K.; BARNES, J. 2001. Solar disinfection of drinking water protects against cholera in children under 6 years of age. Archives of Disease Childhood. 85(4):293-295.

7. CHONG, M.N.; JIN, B.; CHOW, C.; SAINT, C. 2010. Recent developments in photocatalytic water treatment technology: A review. Water Research. 44(10):2997-3027.

8. GOMES, A.; VILAR, V.; BOAVENTURA, R. 2009. Synthetic and natural waters disinfection using natural solar irradiation in a pilot plant studies with CPCs. Catalysis Today. 144(1):55-61.

9. GUMY, D.; MORAIS, C.; BOWEN, P.; PULGARÍN C.; GIRALDO, S.; HAJDU, R.; KIWI, J. 2006. Catalytic activity of commercial $\mathrm{TiO}_{2}$ powders for the abatement of the bacteria ( $E$. coli) under solar simulated light: Influence of the isoelectric point. Applied Catalysis B. 63(1)76-84.

10. HERRMAN, J.M. 2010. Photocatalysis fundamentals revisited to avoid several misconceptions. Applied Catalysis B. 99(3):461-468.

11. LONNEN, J.; KILVINGTON, S.; KEHOE, S.C.; AL-TOUATI, F.; MCGUIGAN, K.G. 2005. Solar and photocatalytic disinfection of protozoan, fungal and bacterial microbes. Water Res. 39(5):877-883.

12. MAHMOODI, N.M.; ARAMI, K.; LIMAEE, N.Y.; GHARANJIG, K.; NOURMOHAMMADIAN, F. 2007. Nanophotocatalysis usin immobilized titanium dioxide nanoparticle: Degradation and mineralization of water containing organic pollutant: Case study Butachlor. Materials Res.Bulletin. 42(5):797-806.

13. MALATO, S.; FERNÁNDEZ, P.; MALDONADO, M.I.; BLANCO, J.; GERNJAK, W. 2009. Decontamination and disinfection of water by solar photocatalysis: Recent overview and trends. Catalysis Today. 147(1):1-59.

14. MARUGÁN, J.; GRIEKEN, R.; PABLOS, C.; SORDO, C. 2010. Analogies and differences between photocatalytic oxidation of chemicals and photocatalytic in- activation of microorganisms. Water Res. 44(3):789796.

15. MARUGÁN, J.; GRIEKEN, R.; SORDO, C.; CRUZ, C. 2008. Kinetics of the photocatalytic disinfection of Escherichia coli suspensions. Applied Catalysis B. 82(1):27-36.

16. QOURZAL, S.; TAMIMI, M.; ASSABBANE, A.; AITICHOU, Y. 2007. Influence de certains ions inorganiques, de l'éthanol et du peroxide d'hydrogène sur la photominéralisation du $\beta$-naphtol en présence de $\mathrm{TiO}_{2}$. Comptes Rendus Chimie. 10(12):1187-1194.

17. QUEK, P.; HU, J. 2008. Indicators for photoreactivation and dark repair studies following ultraviolet disinfection. J. Industrial Microbiology and Biotechnology. 35(6):533-541.

18. RIGA, A.; SOUTSAS, K.; NTAMPEGLIOTIS, K.; KARAYANNIS, V.; PAPAPOLYMEROU, G. 2007. Effect of system parameters and of inorganic salts on the decolorization and degradation of Procion $\mathrm{H}$-exl dyes. Comparison of $\mathrm{H}_{2} \mathrm{O}_{2} / \mathrm{UV}$, Fenton, UV/Fenton, $\mathrm{TiO}_{2} / \mathrm{UV}$ and $\mathrm{TiO}_{2} / \mathrm{UV} / \mathrm{H}_{2} \mathrm{O}_{2}$ processes. Desalination. 211(1):72-86.

19. RINCÓN, A.; PULGARÍN, C. 2004. Effect of pH, inorgánic ions, organic matter and $\mathrm{H}_{2} \mathrm{O}_{2}$ on $E$. coli $\mathrm{K} 12$ photocatalytic inactivation by $\mathrm{TiO}_{2}$ : Implications in solar water disinfection. Applied Catalysis B. 51(4): 283302.

20. RINCÓN, A.; GIRALDO, S.A.; PULGARÍN, C. 2005. Tecnologías solares para la desinfección y descontaminación del agua. Blesa M.A., Blanco J. Eds., Solar Safe Water, Buenos Aires, p.203-219.

21. SATHASIVAN, A.; OHGAKI, S.; YAMAMOTO, K.; KAMIKO, N. 1997. Role of inorganic phosphorous in controlling regrowth in water distribution systems. Water Science and Technology. 35(8):37-44.

22. SMITH, R.J.; KEHOE, S.C.; MCGUIGAN, K.G.; BARER, M.R. 2000. Effects of simulated solar disinfection of water on infectivity of Salmonella typhimurium. Letters in Applied Microbiol. 31(4):284-288.

23. SOMMER, R.; HAIDER, T.; CABAJ, A.; PRIBIL, W.; LHOTSKY, M. 1998. Time dose reciprocity in UV disinfection of crude water for drinking-water production. J. Photochemistry and Photobiology A. 147(3):241-246.

Recibido: Agosto 26 de 2010

Aceptado: Enero 18 de 2011 